\title{
EDUCATION AND URBANIZATION AS CONTROLLING AGENTS OF DOMESTIC VIOLENCE AGAINST WOMEN IN KAMRUP (M) DISTRICT OF ASSAM
}

\author{
Preceileena Koch \\ Research Scholar, Department of Geography, Gauhati University \\ Guwahati, Assam, India
}

\begin{abstract}
Domestic violence is related to injustices against women due to their disadvantageous position in the society. Women have been one of the most vulnerable sections of the society since ages. The proportion and extent of the violence may vary from one place to another which portrays an interesting picture of various factors contributing to such variation. Although in the mainstream society the scenario is improving in terms of number of occurrences of violence against women, however, the picture is not very pleasant in the real world with almost one out of every three women i.e. 35 percent of women of the world experiencing violence of different forms against them. With this perspectives an attempt is made to understand the nature and extent of the domestic violence in Kamrup (M) district of Assam against the women of varying age groups along with the role of education and place of residence as controlling factor towards the same. The study is based on primary survey with data collected through stratified sampling from 110 women from a cross section of the society, which then analysed, and conclusions are derived from the observation. It has been found that more than 72 percent of the women have experienced violence of some form with highest percentage of violence being after marriage, either by the in laws or husbands.
\end{abstract}

Key words: Domestic Violence, Nature and Extent, Education, Rural and Urban Differences

Cite this Article: Preceileena Koch, Education and Urbanization as Controlling agents of Domestic Violence Against Women in Kamrup (M) District of Assam, International Journal of Management, 11(11), 2020, pp 1163-1169.

http://iaeme.com/Home/issue/IJM?Volume=11\&Issue $=12$

\section{INTRODUCTION}

Domestic violence is mostly related to injustices and crimes against women due to their disadvantageous position in the society. It refers to the violence that mostly exist in their 
matrimonial homes [1]. Women, from ages, have been one of the most vulnerable section of the society experiencing violence, exploitations and injustices, both from the family as well as from the society. The proportion and extent of the domestic violence may vary from one place to another depending on several factors, which portray an interesting picture of spatial differences of such violence against women. Although in the mainstream society the scenario is improving in terms of number of occurrences of violence against women, however, the picture is not very pleasant in most parts of the world. One out of every three women experiences violence against them both physical and sexual as well as mental which constitutes 35 percent of the total women of the world [2]. Out of these, most interesting thing lies on the fact that one of the highest percentages of such violence against women occurs within the four walls of their own house in the form of domestic violence. In India, the occurrence of violence against women is a very usual phenomena, where majority of the perpetrators are either their known person or any family members. Girls or women in India are less privileged and, in most cases, they are considered inferior to the latter. The patriarchal society in India have made all customs and values favouring men since the time of Rig Veda and the women have been suffering these discriminations in silence [3]. Every third women, since the age of 15 years starts experiencing domestic violence of various forms in the country [4], which not only effects the women physically but also mentally and psychologically. India, being predominantly a patriarchy society, somehow have not been able to retain the status of women in many parts of the region, despite of its various development. Nevertheless, the situation may be exceptional in some cases. The scenario of Assam is also a not very pleasant one however the situation here is little better than many parts of the country. More than 72 percent of the women have experienced violence against them in the region (primary survey, 2020). The forms and extent of violence may vary depending on various factors like age, education, place of residence etc. The incidence of violence against women have been constantly showing an increasing trend with 21500 registered cases of various crimes against women in the year 2016, which subsequently increased to 21,603 to 27,064 in 2017 and 2018 respectively [5]. Among these statistics, the share of domestic violence is among one of the highest one, apart from rape and abduction. The women of this part of the country often claims that they are mostly neglected and are left behind the mainstream India in availing many opportunities and rights. With these backgrounds, an attempt is made in the current study to evaluate and understand the rate and extent along with the various aspects related to the domestic violence against women in various places of Kamrup (M) district of Assam, particularly the effect of place of residence (rural or urban) and education on such violence against women. Although some studies related to domestic violence against women have been carried out, but this study tries to evaluate the role of education and urbanisation in controlling such violence. Also, this paper will pave way for further studies of the same.

\section{DATABASE AND METHODOLOGY}

The study is primarily based on primary data collected through stratified random sampling method where 110 women of varying age groups (i.e. below 18 years, 18 to 35 years, 35 to 45 years and above 45 years) were interviewed through structured schedule, either through direct interview or telephonic interview. Of these total women, 55 women were predominantly from rural areas comprising both literate and illiterate; and another 55 women were from urban area comprising again of both literate and illiterate women, which enable us to make a comparative study between rural and urban areas regarding the same. Several secondary data and information were also referred, to increase our understanding and develop a perspectives in relation to such domestic violence prevailing in the region of Kamrup (M) of Assam, and to validate the data collected through the primary survey. The data so collected through primary 
and secondary sources have been processed, structured, analyzed and represented using various simple yet meaningful statistical techniques wherever necessary. Along with that conclusions are made from the deriving results and the personal field observations.

\section{ANALYSIS AND DISCUSSION}

\subsection{Nature of Domestic Violence}

More than 72 percent of the women surveyed, of the varying age groups have informed of experiencing domestic violence of different forms at some point of their lives with majority of the violence occurring after marriage. Almost 31 percent of the women have accepted that violence against them have increased after their marriage where the perpetrator is mostly their husbands and, in some cases, are their husband's family. Only a few, less than 12 percent women have reported to experience domestic violence in their own parental house [primary survey,2020]. The greater picture of India gives an alarming notification where more than 70 percent of the women who have experienced violence have never sought help or did not even inform anyone [6]. Rest among the ones those who have sought help, less than 15 percent have reached out to the relevant authorities, and majority reaching out to their immediate families only. The situation is not vey different in case of Assam too, where majority of the respondents were hesitant to talk about their experiences related to the domestic violence because of the societal norms and beliefs that is prevalent in the society since ages. Such violence not only effects the women physically but also mentally, which also paves way for many other chronic diseases and psychological distress. But domestic violence despite being the most pervasive is the least recognized human rights abuse in the world [7]. In Kamrup (M) district of Assam, highest percentage of domestic violence i.e. 34 percent is experienced by females between the age group of 18-35 years and least by females above 45 years of age [primary survey,2020]. This may be accredited to the fact that 18-35 years age group mainly comprised of the newly married couples where problems of husband's or in laws' tortures or matters related to dowry are triggered after the marriage [Table 1].

Table 1 Percentage of women experiencing domestic violence of different age groups in

Kamrup (M), Assam

\begin{tabular}{|c|c|}
\hline Age Groups & $\begin{array}{c}\text { Percentage of Women experiencing domestic violence of } \\
\text { different forms }\end{array}$ \\
\hline Below 18 years & 28 \\
\hline $18-35$ years & 34 \\
\hline $35-45$ years & 25 \\
\hline Above 45 years & 13 \\
\hline
\end{tabular}

Source: Primary Survey, 2020

Almost 25 percent of the women interviewed, have become habituated to the domestic violence and have started to accept it because of lack of support and awareness. The patriarchal norms of the society have made the situation even more difficult for the women. Among these, a few of them who were courageous enough to go against the societal norms and reached out to relevant authorities like police or NGOs, many of them were brutally excluded or blamed by the mainstream society. Even in some cases, the victims own family disowned them, as mentioned by Rashmi, one of the respondent of sonapur, ' when I tried to say my parents about my husband's torture, my parents have asked me to adjust somehow. When I refused, I was disowned by my husband as well as my own family and was compelled to live alone along with 
Education and Urbanization as Controlling Agents of Domestic Violence Against Women in Kamrup (M) District of Assam

my 2 years daughter somehow working on other people's lands or houses.' The women are subjected to various kinds of violence amidst the four walls of their house. The highest percentage of women are subjected to violence acts of husband ( 44 percent) followed by sexual harassment (22 percent), physical abuse (18 percent) and other forms of violence (16 percent), but due to prevailing situations in the society, many are bound to remain shut and make terms with their difficulties. Among all these injustices, a very important thing to be noted is that, almost more than 90 percent of the perpetrators are very well-known intimate partners or relatives of the victims or any other neighbours [Primary survey,2020].

\subsection{Role of Education in Domestic violence}

Education play a great role in determining people's perspectives and approaches to various aspects of lives. Domestic violence in the region is considerably high and more extreme in case where the respondents and the perpetrators are mostly illiterate [Figure 1].

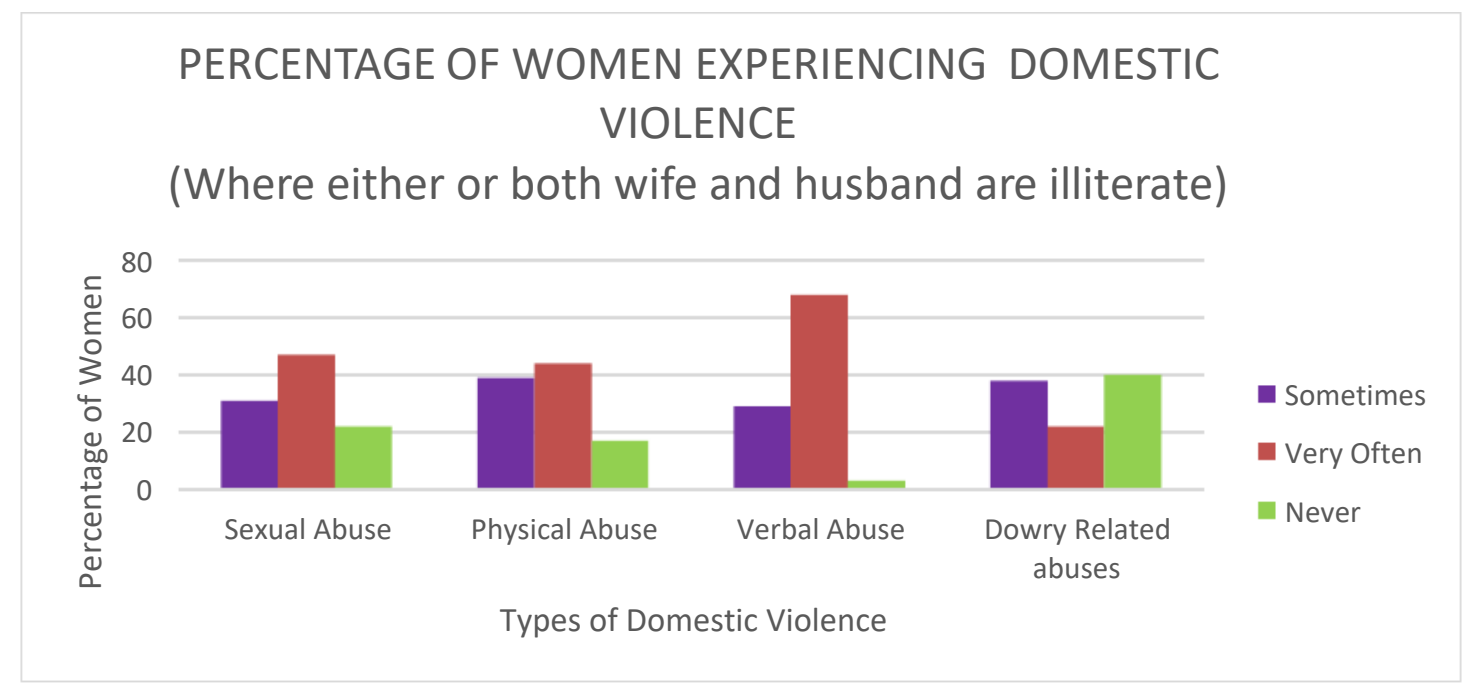

Figure 1 Percentage of women Experiencing Domestic Violence Where either or both husband and wife are illiterate

Source: Primary Survey, 2020

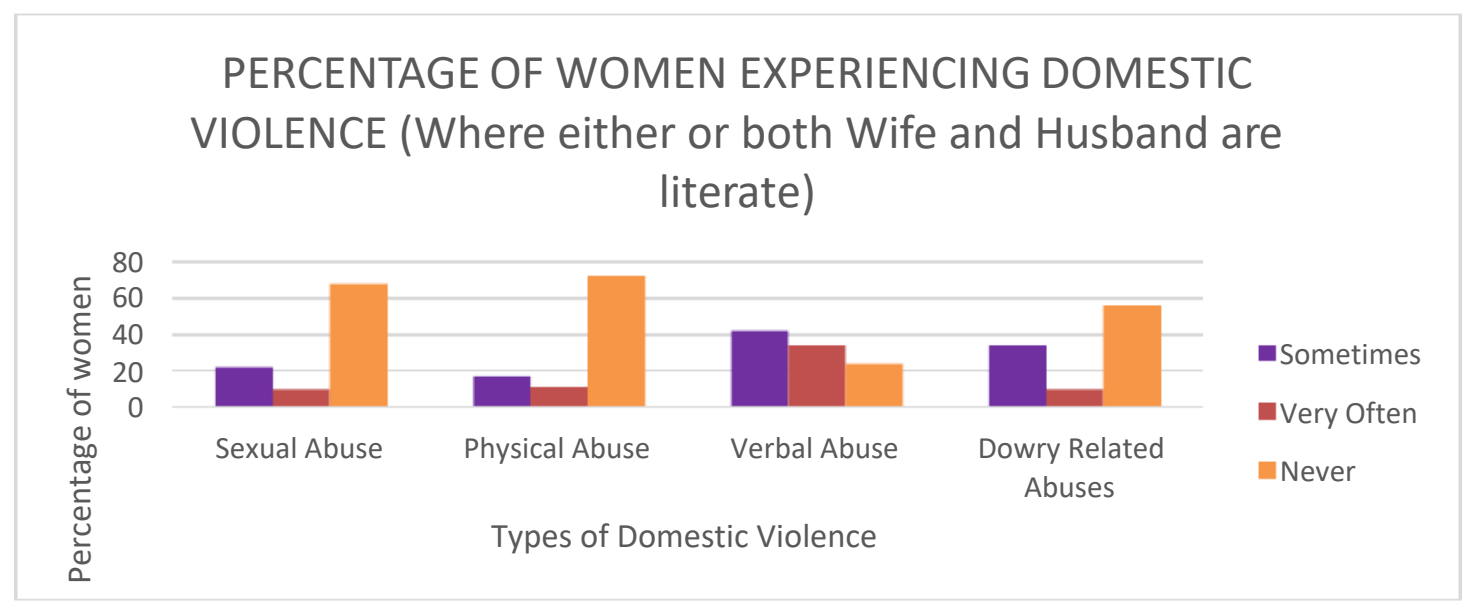

Figure 2 Percentage of women Experiencing Domestic Violence Where either or both husband and wife are literate

Source: Primary Survey, 2020 
Both Figure 1 and 2 portrays the clear picture that the rate of occurrence of various forms of domestic violence are much less among the literate couples compared to the illiterate couples where either or both husband and wife are illiterate. This is mainly because education not only develops knowledge but also helps to broaden the approaches and outlooks of people's view and thinking. The women whose husbands are literate, are found to be less subjected to usual domestic violence. Moreover, almost 70 percent of the women [Primary Survey, 2020], that were literate were more open and were more aware of their rights and procedures which reduces their vulnerability towards violence against them.

\subsection{Role of Residence in Domestic Violence}

The primary survey for the current study was conducted considering women from both rural and urban areas of the district to get a comparative picture between the two. The rate of occurrence of domestic violence against women is comparatively higher in case of rural areas where majority of the women are of more accepting nature of such behaviours [8]. From the primary survey, it has been found that the rate of domestic violence against women in Assam is less by 31 percent in urban areas than the rural areas. Almost 88 percent of the women interviewed from the rural areas have experienced domestic violence of some form or the other, mostly those related to physical and verbal abuses. The situation is even more worsened if the women or the perpetrator or both does not have any form of education as it is evident from Figure 1. This may be due to lack of understanding or knowledge among the committers about the drawbacks of such acts which not only effects the women physically but, in many cases, it effects the women mentally and psychologically. The women of the rural areas are even more accepting and habituated to such acts of violence and to them such acts have either become usual acts or they don't come out and speak about it due to shame, fear or societal norms. However, the picture is little better in the urban areas where 62 percent of the interviewed women, which is much lesser than the rural areas, have experienced domestic violence in their lives. In such cases, majority are related to verbal abuses with very less rate of physical or sexual abuses compared to the rural areas. This may be accredited to the fact that women in the urban areas have got a higher status in the society compared to the rural areas, along with that, more literate people encompasses such areas which assures better lifestyles and economic securities that in turn plays a great role in reducing the rate and extent of various types of violence against the women in the region.

\section{CONCLUSION}

From the foregoing discussion, it is clear that domestic violence is prevalent in the region since ages at varying rate and extent. Almost 72 percent of the women interviewed, both from rural and urban areas comprising both literate and illiterate, have experienced domestic violence at some point of their lives at varying rates. In spite of such high percentage of occurrence of domestic violence in the region, the matter is not viewed with that much of importance and is often neglected by most people, even by the victims themselves which not only suppress the matter but also encourages more occurrence of such acts. Women in most societies, particularly in the Kamrup district is one of the most vulnerable section of the society. The irony is, people of the region worships different goddess with utmost faith and beliefs but those same people fails to show the respect and courtesy to the women in their real lives. The situation in the region is such that many women, almost 32 percent of the women have accepted such violence as a part of their lives, 37 percent of the women are scared or shy to come forward and speak and seek for their justice, 21 percent of the women remains confused and are unaware of their legal rights and provisions to deal with the situation and only less than 10 percent of the women come forward and stand against such violence (Primary Survey, 2020). Although Assam experiences a comparatively lesser domestic violence against women, however the number of cases related 
to this have been constantly increasing. A very important point to be noted here is that although the rate of marital rape is found not to be very significant compared to other violence according to the acquired data found from the statistical handbook of Assam, however it is one of the most prevalent form of violence against the women but most women doesn't understand it and accepts it thinking it to be their husband's right or are hesitant to speak about it. More than 31 percent of the women have reported of experiencing violence against them mainly after marriage and as already mentioned, in most cases perpetrators are known to the victims. They are either the victim's husband or in laws or any other family friends or relatives about whom the victims are well aware of.

However, from the present study, it is evident that education acts as a driving force and controlling agent of domestic violence against women. In most cases where the husband or in laws were educated or literate, portrays lesser rate of violence against the women which may be due to their broader perspectives and awareness. In cases where both husband and wives are literate least number of violence against the women have been recorded. When women are educated or literate, they are then coming out more readily and speaking about the injustices happening to them which also gives a push towards decreasing the rate of violence against them. However, if anyone among the husband or wife is illiterate, particularly the wife, then in such cases the domestic violence against the woman is highest. In case of the place of residence, as already mentioned, the women of the rural areas are less privileged compared to the urban areas as it is found from the current study that the incidence of domestic violence against the women is less by 31 percent in the urban areas compared to the rural areas (Primary Survey, 2020). The people in the urban areas are more literate and educated, more economically secured and are more socially sound being which therefore decreases the rate of violence against the women in such areas. Apart from this the women themselves in the urban areas are much open about such issues which help in motivating and influencing many other women to speak up about such violence against them. Therefore, women in the urban areas are less vulnerable or prone to such violence against them. All these discussions suggest us that if properly utilized and channelled then both, urbanization along with education can act as a driving force in reducing the rate of domestic violence against the women and bring a drastic change to the age old societal norms and practices for making a better society to live in. There must be some awareness programme for the women as well as perpetrators to make the women aware about their available opportunities and also for the perpetrators to help them be aware and understand the rights of the women or on whom they are committing the violence. If appropriate measures are adopted at the government and non-government levels, then various problems associated with domestic violence against the women can be addressed and subsequently be resolved.

\section{REFERENCES}

[1] Sahoo, H. and Pradhan, M. R. Domestic Violence in India: An Empirical Analysis, Man in India, 89 (3), 2009, 303-321. https://www.researchgate.net/publication/230859625_Domestic_violence_in_India_An_empir ical_analysis

[2] World Health Organizaton: Violence Against Women (2017).https://www.who.int/news$\mathrm{room} /$ fact-sheets/detail/violence-against-women

[3] Sharma, I. Violence Against Women: Where are the Solutions?, Indian Journal of Psychiatry, 57 (2), 2015, 131-139. https://www.ncbi.nlm.nih.gov/pmc/articles/PMC4462781/ 
[4] Kirti, S. Every Third Women in India Suffers Sexual, Physical Violence at Home, 2018.https://www.news18.com/news/india/the-elephant-in-the-room-every-third-woman-inindia-faces-domestic-violence-1654193.html

[5] Statistical Handbook of Assam 2016-2019

[6] Radhakrishnan, V., Sen, S. and Singaravelu, N. Domestic Violence Complaints at a 10 year high during Covid-19 Lockdown, The Hindu, 2020.https://www.thehindu.com/data/data-domesticviolence-complaints-at-a-10-year-high-during-covid-19-lockdown/article31885001.ece

[7] Heise, L., Ellsberg, M. and Gottemoeller, M. Population Reports: Ending Violence Against Women,

1999.https://www.researchgate.net/publication/287170875_Population_reports_Ending_violen ce_against_women

[8] Leonard, A., Nkwo, P. and Iyoke, C. Comparison of Domestic Violence Against Women in Urban versus Rural areas of South East Nigeria, International Journal of Women's Health, 2014, 865-872.

https://www.researchgate.net/publication/266674405_Comparison_of_domestic_violence_aga inst_women_in_urban_versus_rural_areas_of_southeast_Nigeria\#:- $:-\bar{t}$ text $=$ The $\% \overline{2} 0$ prevalence $\% 20$ of $\% 20 \mathrm{DV} \% 20$ among, $23.5 \% 25 \% 3 \mathrm{~B} \% 20 \mathrm{P} \% 3 \mathrm{D} 0.05$. 